\title{
Aplikasi Geografis Organisasi Islam di Kementrian Agama Kecamatan Pelaihari Berbasis Web Mobile
}

\author{
Utami Rahayu Ningsih, Herpendi, Muhammad Noor* \\ Program Studi Teknik Informatika, Politeknik Negeri Tanah Laut \\ Email: muhammadnoor@politala.ac.id*,herpendi@politala.ac.id
}

\begin{abstract}
Abstrak
Kementerian Agama mempunyai fungsi yang salah satunya adalah menaungi beberapa organisasi keislaman, kecamatan pelaihari memiliki budaya keislaman yag cukup kental sehingga memiliki beberapa organisasi keislaman yang cukup banyak. Sistem yang berjalan saat ini di Kementrian Agama Kecamatan Pelaihari masih mengunakan sistem manual dalam mencatatan informasi organisasi islam, sehingga informasi tentang namanama organisasi islam, lokasi organisasi islam, dan struktur organisasi islam tidak di ketahui oleh masyarakat. Hal tersebut dapat menyebabkan terhambatnya masyarakat yang ingin mengetahui lebih lanjut tentang organisasi keislaman, Sehingga diperlukan suatu sistem untuk masyarakat agar bisa mengetahui informasi organisasi keislaman di kecamatan pelaihari, agar masyarakat dapat mengakses Aplikasi Geografis organisasi kislaman di Kecamatan Pelaihari Berbasis Web Mobile. Aplikasi ini dirancang dengan menggunakan Data Flow Diagram, Flowchart serta dirancang menggunakan Entity Relationship Diagram (ERD) dan menggunakan bahasa pemrograman Hypertext Preprocessor (PHP). Diharapkan dengan dibuatnya plikasi ini masyarakat pelaihari dapat mengakses semua informasi yang berkaitan dengan kegiatan atau kebedaan organisasi keislaman di kecamatan Pelaihari.
\end{abstract}

Kata kunci : Islam, Organisasi, Web Mobile.

\begin{abstract}
The Ministry of Religion has a function, one of which is to oversee several Islamic organizations. Pelaihari District has a strong Islamic culture so that it has quite a lot of Islamic organizations. The system currently running at the Ministry of Religious Affairs in Pelaihari Regency still uses a manual system for recording information on Islamic mass organizations, so that information regarding the names of Islamic organizations, the location of Islamic organizations, and the structure of Islamic organizations is not yet known by the public. This can create obstacles for people who want to know more about Islamic Organizations, so a system is needed for the public to find out information on Islamic Organizations in Pelaihari District, so that people can access the Geographical Application of Islamic Organizations in Pelaihari Regency based on Web Mobile. This application is designed using Data Flow Diagrams, Flowcharts and is designed using Entity Relationship Diagrams (ERD) and uses the Hypertext Preprocessor (PHP) programming language. It is hoped that with this application the Pelaihari community can access all information related to activities or differences in Islamic organizations in Pelaihari District.
\end{abstract}

Keyword : Islam, Organizations, Mobile Web 


\section{PENDAHULUAN}

Berdasarkan peraturan presiden republik Indonesia Nomor 83 tahun 2015 tentang Kementerian Agama yang menyatakan kedudukan, tugas dan fungsi dalam pasal 2 menyatakan Kementerian Agama mempunyai tugas menyelenggarakan urusan pemerintahan di bidang agama untuk membantu Presiden dalam menyelenggarakan pemerintahan negara. Pasal 3 ayat 2 menyatakan koordinasi pelaksanaan tugas, pembinaan, dan pemberian dukungan administrasi kepada seluruh unsur organisasi di lingkungan Kementerian Agama. Tujuan Organisasi pembaruan islam di Kalimantan Selatan untuk menghimpun, membahas, dan memecahkan masalah hukum islam. Organisasi islam membutuhkan karakter dalam hukum islam yang otonom, mandiri, bebas dari politik, dikalangan ulama tradisional. Sekelompok organisasi islam mencurahkan beberapa pengkajian agama, menyebarkan praktek islam yang benar dan kepatuhan dalam menjalankan hukum islam.

Masyarakat kecamatan pelaihari memiliki budaya keislaman yag cukup kental sehingga memiliki beberapa organisasi keislaman yang cukup banyak. Ada 15 Organisasi Islam yang ada di Tanah Laut Kecamatan Pelaihari seperti Majelis Ulama Indonesia (MUI), Nahdlatul Ulama Indonesia (NUI), Lembaga Dakwah Islam Indonesia (LDII), Muhammadiyah, Nasiatul Aisiyah, Aisiyah, Fatayat NU, Muslimat NU, Gerakan Pemuda Ansor (G. P Ansor), Ikatan Pemudan Nahdlatul Ulama (IPNU), Ikatan Pemuda Putri Nahdlatul Ulama (IPPNU), Badan Komunikasi Pemuda Remaja Masjid Indonesia (BKPRMI) ,Lembaga Pengembangan Tilawatil Qur'an (LPTQ), Pergerakan Mahasiswa Islam Indonesia (PMII), dan Wanita Islam.

Berdasarkan budaya keislaman yang kental di kecamatan pelaihari, masyarakat mengharapkan dapat mengakses informasi tentang organisasi keislaman yang berada di kecamatan pelaihari, namun sistem yang berjalan saat ini di kementerian Agama kecamatan pelaihari menggunakan catatan yang diarsipkan dalam mencatat keberadaan dan kegiatan organisasi kesilaman, sehingga banyak dari masyarakat yang kurang mengetahui informasi tentang organisasi keislaman di kecamatan pelaihari. Solusi yang diambil penulis adalah membangun sebuah Aplikasi Geografis Organisasi Islam di Kecamatan Pelaihari Berbasis Web Mobile, yang didalamnya mempermudah kerja dari Kementrian Agama yang ada di Pelaihari jika ingin menambahkan organisasi dengan lewat aplikasi yang telah dibangun ini, lalu masyarakat juga tidak perlu datang ke Kementrian Agama yang ada di Pelaihari untuk menanyakan tentang organisasi ataupun yang lainnya, masyarakat bisa mengakses di smartphone mereka sebuah Aplikasi Geografis Organisasi Islam di Kecamatan Pelaihari Berbasis web mobile.

Berdasarkan permasalah tersebut penulis dapat melihat betapa pentingnya pengolahan aplikasi pencatatan organisasi islam untuk informasi pada kementrian agama di kecamatan pelaihari. Sehingga penulis tertarik mengangkat judul "Aplikasi Geografis Organisasi Islam di Kecamatan Pelaihari Berbasis Web mobile.

\section{METODE PENELITIAN}

\section{Metode Pustaka}

Penulisan ini dilakukan dengan cara membaca buku literatur dan mengutip, menyimpulkan bacaan yang diperoleh dari buku, jurnal, maupun artikel di internet yang berhubungan dengan Aplikasi Geografis Sejarah Organisasi Islam di Kecamatan Pelaihari Berbasis Web Mobile yang dibangun.

\section{Metode Observasi}

Metode observasi dilakukan dengan mengumpulkan data dan informasi yang dibutuhkan dalam perancangan, pengembangan sistem aplikasi. Observasi pada aplikasi yang berjalan dilakukan dengan mengumpulkan data dan informasi yang dibutuhkan dalam perancangan, pembuatan sistem serta 
proses aplikasi organisasi islam di kecamatan pelaihari dengan melihat secara langsung kelokasi organisasi dan memahami nama-nama organisasi, tempat organisasi dan struktur organisasi yang sudah berjalan di Kecamatan Pelaihari.

\section{Metode Wawancara (Interview)}

Metode wawancara merupakan suatu kegiatan yang dilakukan dengan mencari sebuah informasi kepada narasumber yang berkompeten dibidangnya, mencari dan pemberi data dapat langsung bertukar pikiran. Pada metode ini, penulis melakukan wawancara dengan kementrian agama yaitu ibu Sri yang mendata setiap organisasi islam di Kecamatan Pelaihari. Hasil wawancara dari organisasi islam membahas tentang nama-nama setiap organisasi islam, tempat organisasi islam berada, stuktur setiap organisasi islam.

\section{HASIL DAN PEMBAHASAN}

Kegiatan yang berjalan saat ini di kementerian Agama kecamatan Pelaihari.

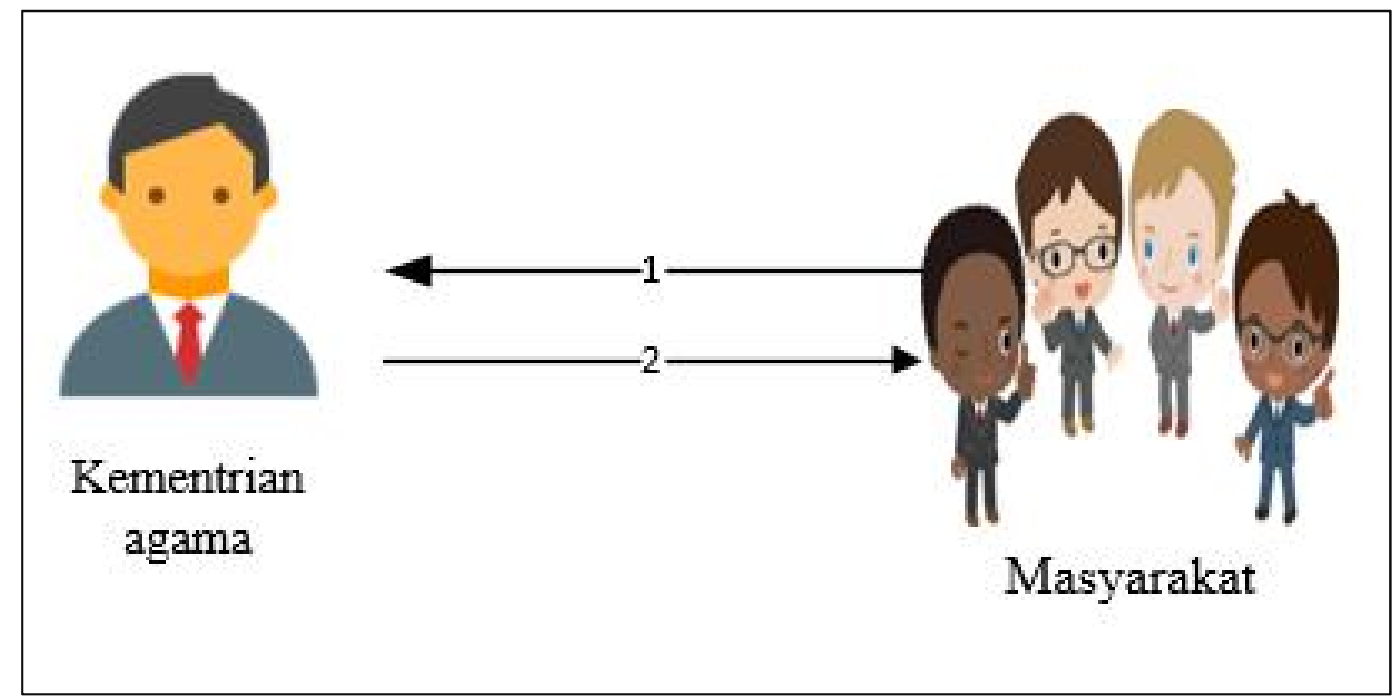

Gambar 1. Analisis yang berjalan

Penjelasan Aplikasi Geografis Organisasi Islam di Kecamatan Pelaihari:

1. Masyarakat akan mendapatkan data organisasi islam dari Kementrian Agama.

2. Kementrian Agama akan memberikan data setiap organisasi-organisasi yang berada di Kecamatan Pelaihari. 
Analisis yang diusulkan

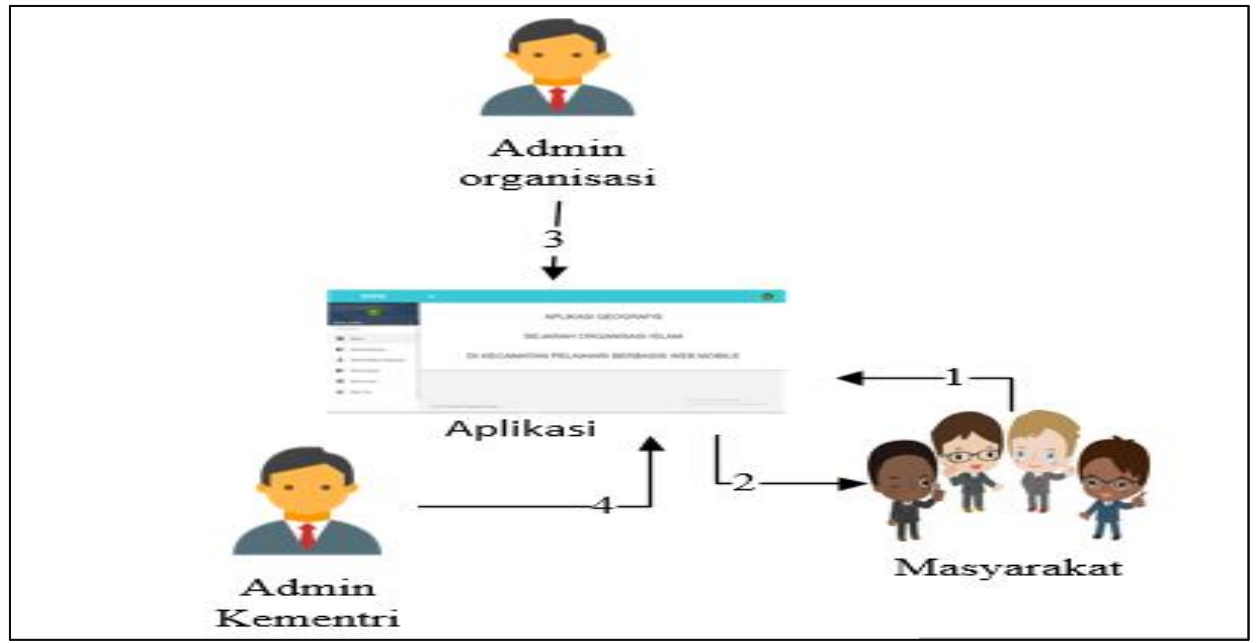

Gambar 2. Analisis yang diusulkan

Penjelasan dari sistem yang diusulkan dari Aplikasi Geografis Organisasi Islam di Kecamatan Pelaihari Berbasis Web Mobile:

1. Masyarakat hanya bisa melihat data atau tampilan setiap organisasi islam yang berada di internet yang berupa organisasi, struktur organisasi, dan lokasi.

2. Aplikasi Geografis Organisasi Islam di Kecamatan Pelaihari akan memberikan data kepala free user yang berupa sejarah setiap organisasi, struktur organisasi, dan lokasi.

3. Admin organisasi hanya bisa mendaftarkan anggota yang inggin ikut didalam organisasi islam yang akan dia ikuti di kecamatan Pelaihari.

\section{Entity Relationship Diagram (ERD)}

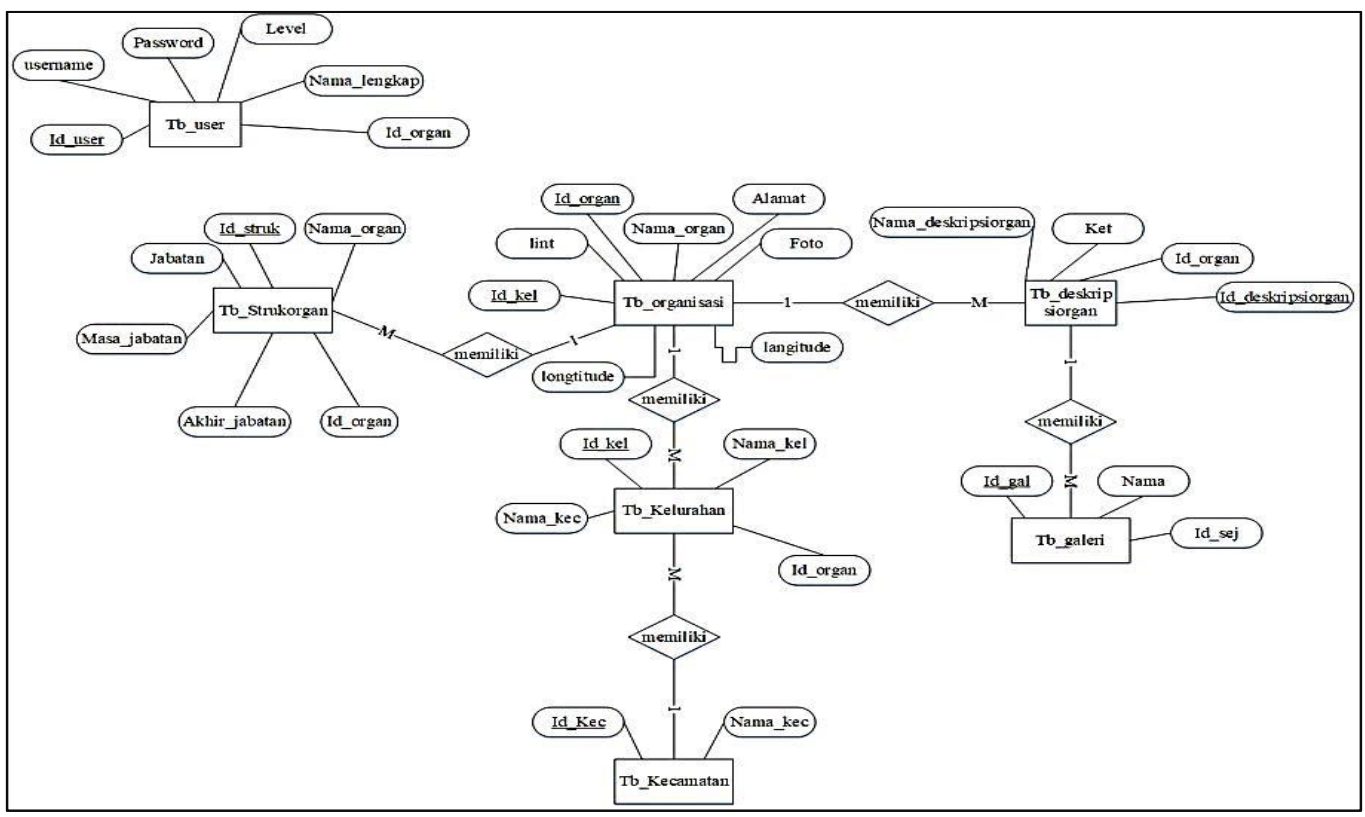

Gambar 3 Rancangan ERD (Entity Relationship Diagram) 
Gambar 3 memiliki alur diagram ERD dimana terdapat beberapa entitas yang pertama pada entitas tb_user memiliki atribut id_user (primary key), nama_lengkap, username, password dan level. Tb_strukorgan memiliki atribut id_strukorgan (primary key), nama_struk, jabatan, thun_dilantik, thun_berakhir, id_organ (Foreign Key). Tb_deskripsiorgan memiliki atribut id_deskripsiorgan (primary key), id_organ (foreign key), nama_deskripsiorgan, ket. Tb_organisasi memiliki atribut id_organ (primary key), nama, alamat, id_kel (foreign key), foto, longtitude, langitude. Foto kelurahan memiliki atribut id_kel (primary key), nama kel, id_kec (foreign key). Tb_kecamatan memiliki atribut id_kec (primary key), nama_kec. Tb_galeri memiliki atribut id_gal (primary key), nama_gal, id_sej (foreign key).

\section{Diagram Konteks}

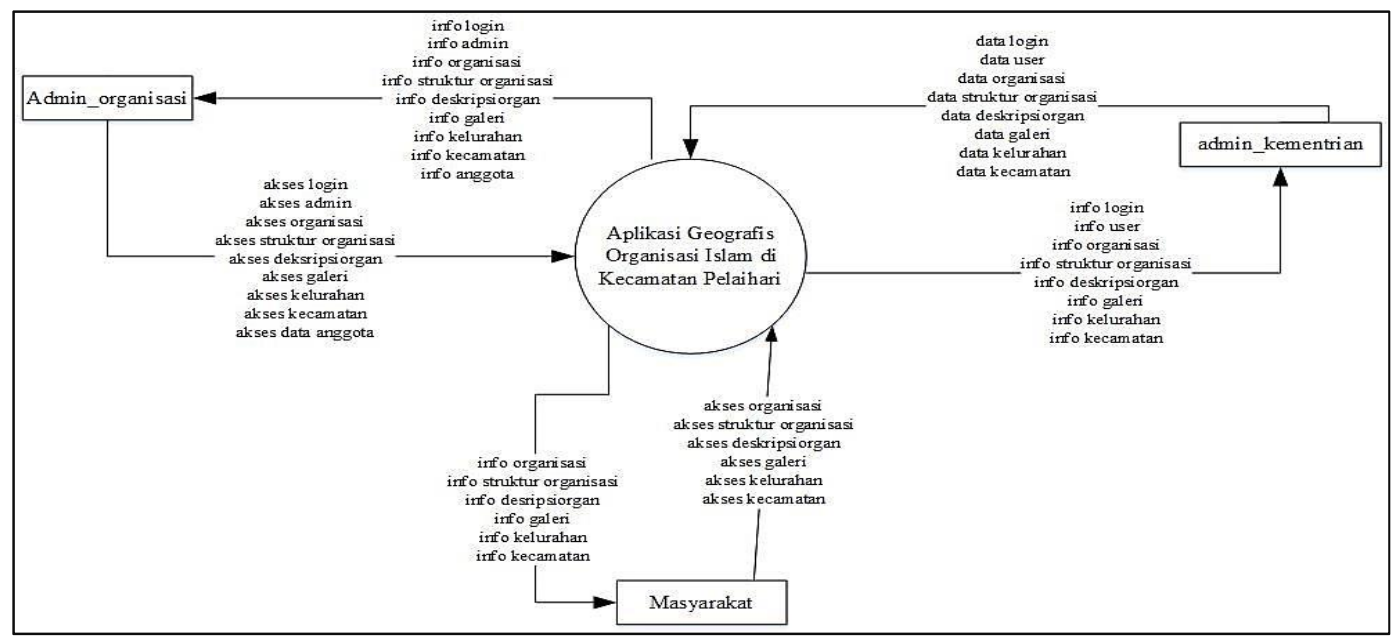

Gambar 4 Diagram Konteks

Gambar 4 memiliki tiga hak akses yaitu free user, admin_organisasi dan admin_kementrian. Masyarakat hanya bisa melihat data tampa login, admin_organisasi hanya bisa melihat data nama anggota dan mengedit, dan admin_kementrian yang memasukkan data dari setiap organisasi seperti deskripsiorgan, struktur-struktur organisasi, nama-nama organisasi, dan foto setiap organisasi.

\section{Implementasi Sistem}

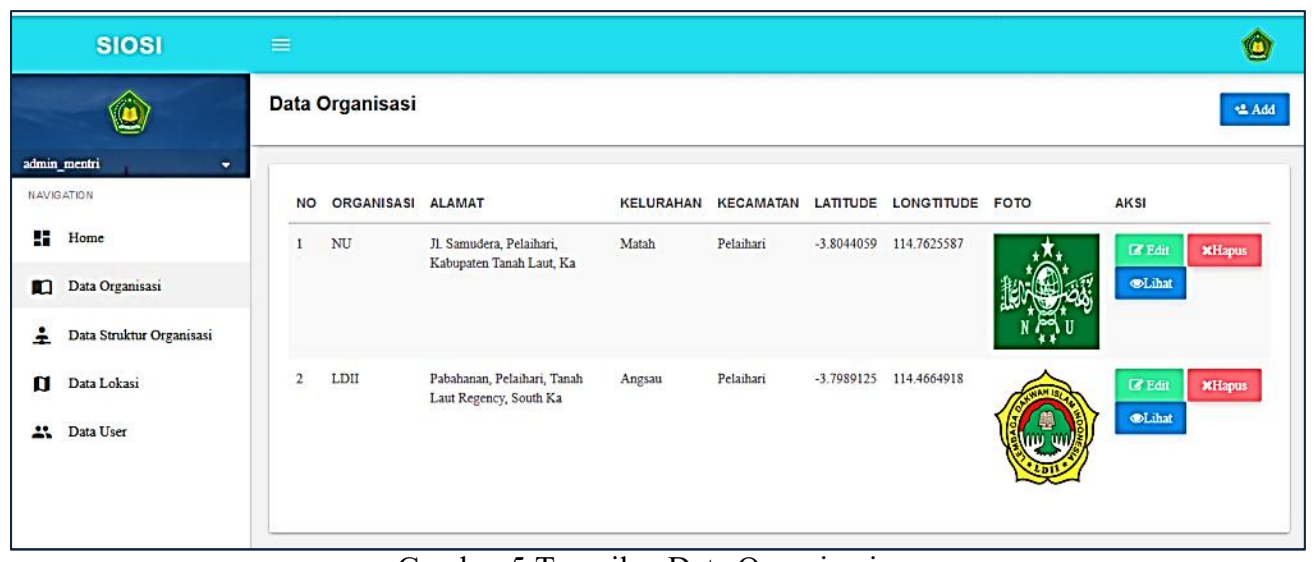

Gambar 5 Tampilan Data Organisasi 
Gambar 5 penjelasan implementasi sistem data organisasi yang mana menampilkan tambah data edit, hapus dan lihat. Didalam data organisasi akan menampilkan data yang telah di tambahkan berupa no, organisasi, alamat, kelurahan, kecamatan, latitude, longtitude dan foto.

\section{Tampilan Data Struktur Organisasi}

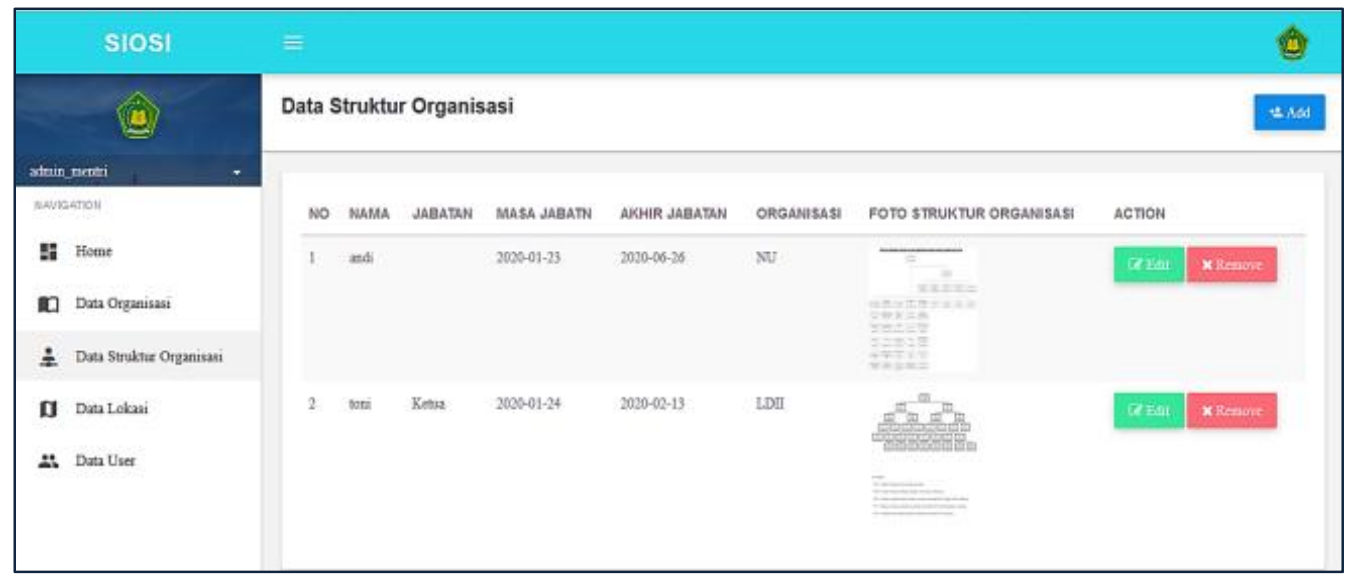

Gambar 6 Tampilan Data Struktur Organisasi

Gambar 6 penjelasan implementasi sistem data struktur organisasi yang mana menampilkan tambah data edit dan hapus data. Didalam data struktur organisasi akan menampilkan data yang telah di tambahkan berupa no, nama, jabatan, masa jabatan, akhir jabatan, organisasi foto struktur organisasi kecamatan pelaihari.

\section{Tampilan Data Lokasi}

\begin{tabular}{|l|l|l|l|l|l|}
\hline \multicolumn{2}{|c|}{ SIOSI } & Data Lokasi & & & \\
\hline
\end{tabular}

Gambar 7 Tampilan Data Lokasi

Gambar 7 penjelasan implementasi sistem data lokasi yang mana menampilkan tambah data edit dan hapus. Didalam data organisasi akan menampilkan data yang telah di tambahkan berupa no, kelurahan dan kecamatan. 


\section{Tampilan Data User}

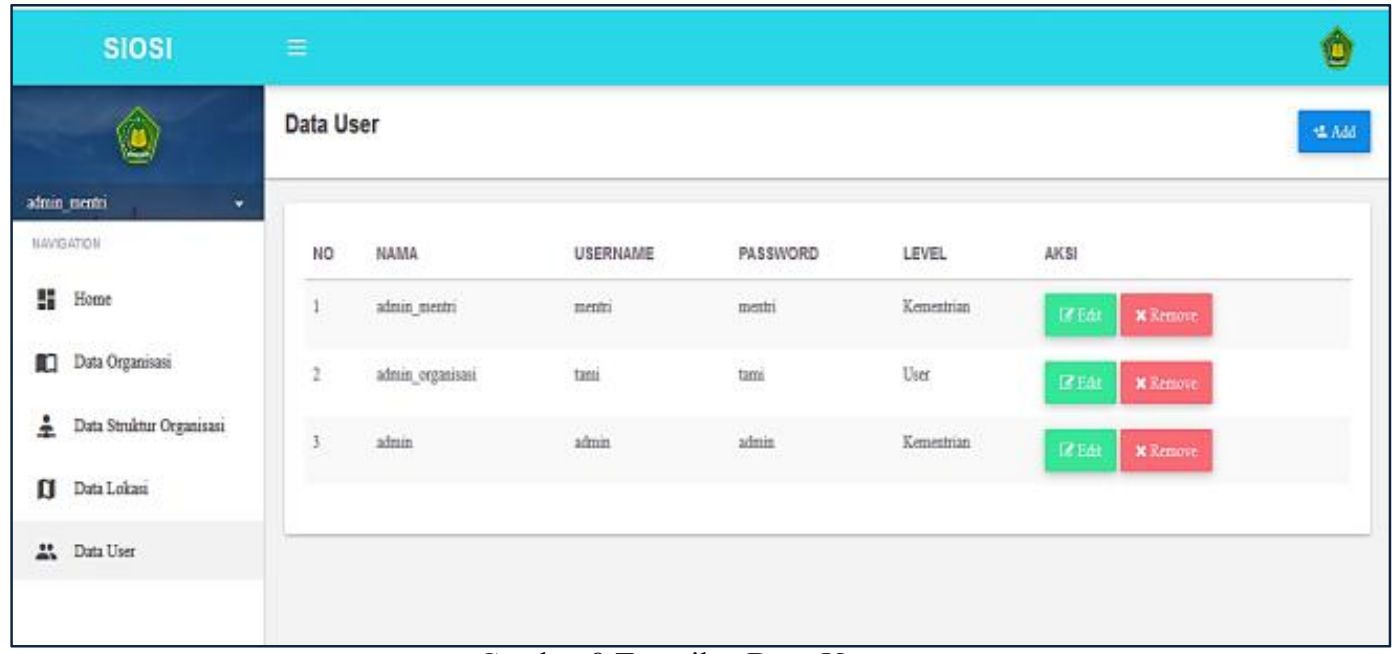

Gambar 8 Tampilan Data User

Gambar 8 penjelasan implementasi sistem data user yang mana menampilkan tambah data edit dan hapus. Didalam data user akan menampilkan data yang telah di tambahkan berupa no, nama, username, password dan level.

\section{KESIMPULAN}

Berdasarkan pembahasan tentang Aplikasi Geografis Organisasi Islam di Kementrian Agama Kecamatan Pelaihari Berbasis Web Mobile, maka diperoleh beberapa kesimpulan:

Telah terbangun sebuah aplikasi geografis organisasi Islam di kecamatan Pelaihari berbasis web mobile yang dirancang dengan menggunakan Data Flow Diagram, Flowchart serta penyimpanan data menggunakan database MySQL, basis data menggunakan Entity Relationship Diagram (ERD) dan menggunakan bahasa pemrograman Hypertext Preprocessor (PHP), dengan terbangunnya system aplikasi ini maka dapat mempermudah masyarakat yang ingin mengakses informasi baik berupa tataletak dan kegiatan sebuah organisasi keislaman di kecamatan pelaihari melalui handpone mereka dimanapun dan kapanpun. Melalui aplikasi ini juga dapat mempermudah pihak kementerian Agama kecamatan pelaihari dalam melakukan pencatatan dan pendataan secara terkomputerisasi.

\section{DAFTAR PUSTAKA}

Chan, S. (2017). Membuat Aplikasi Database dengan PowerBuilder 12.6 MYSQL. In S. Chan, Membuat Aplikasi Database dengan PowerBuilder 12.6 MYSQL (p. 12). Jakarta: PT. Alex Media Komputindo.

Rhomadhona, H. (2018). Penerapan Teknologi QR Code Berbasis Web untuk Absensi Pegawai pada BKPSDM Kabupaten Tanah Laut. Jurnal Humaniora Teknologi, 4(1).

Iswandy, E. (2015). Sistem Penunjang Keputusan untuk Menentukan Penerimaan Dana Santunan Sosial Anak Nagari dan Penyalurannya Bagi Mahasiswa dan Pelajar Kurang Mampu di Kenagarian Barung-Barung Balantai Timur. Balantai Timur: Jurnal TEKNOIF Vol. 3/ No. 2/ Oktober 2015, ISSN : 2338-2724.

Kusumaputri, S. E. (2018). Komitmen Pada Peubahan Organisasi. In S. E. Kusumaputri, Komitmen Pada Peubahan Organisasi (pp. 5,6,7). Yogyakarta: CV Budi Utama. 
Nova, H. A. (2011). Panduan Lengkap Internet Lewat Ponsel Java. Dalam H. A. Nova, Panduan Lengkap Internet Lewat Ponsel Java (hal. 2). Jakarta: PT Alex Media Komputindo.

Nurcholish, A. (2018). Membangun Database Arsip Persuratan Menggunakan Pemrograman PHP dan MYSQL. Jawa Barat: CV Jejak.

Santoso, H. (2010). Membuat Multiaplikasi Menggunakan Visual Basic 6. In H. Santoso, Membuat Multiaplikasi Menggunakan Visual Basic 6 (p. 9). Jakarta: Elex Media Komputindo.

Termudi, E. (2005). Islam dan Radikalisme di Indonesia. Jakarta: Lipi Press Anggota IKAPI.

Watung, I. D. (2014). Perancangan Sistem Informasi Data Alumni Fakultas Teknik Unsrat Berbasis Web. In I. D. Watung, Perancangan Sistem Informasi Data Alumni Fakultas Teknik Unsrat Berbasis Web (pp. ISSN 2301-8402). Jakarta: E-journal Teknik Elektro dan Komputer (2014).

Yuhefizar, Mooduto, H., \& Hidayat, R. (2009). Cara Mudah Membangun Website Interaktif Menggunakan Content Management System Joomla (1 ed.). Jakarta: Elex Media Komputindo. 